\title{
Symptoms and Care Satisfaction in Patients Who Underwent Coronary Artery Bypass Graft Surgery
}

\author{
Tugce Bozkurt ${ }^{1}$, Rabia Saglam ${ }^{2}$ [ \\ ${ }^{1}$ Bilgi University, School of Health Service, Department of Anaesthesia, Istanbul, Turkey. \\ ${ }^{2}$ Maltepe University, School of Nursing, Istanbul, Turkey.
}

Correspondence Author: Tugce Bozkurt

E-mail: tugce.bozkurt@bilgi.edu.tr

Received: 28.10.2020 Accepted: 19.04.2021

\begin{abstract}
Objective: This study was conducted to investigate of symptoms and care satisfaction in patients who had a coronary artery bypass graft (CABG) surgery.

Methods: The study population consisted of patients who had a coronary artery bypass graft surgery in a public and a foundation hospital in Istanbul between December 2018 and May 2019 and the study sample 176 patients who met the inclusion criteria and agreed to take part in the study. The study data were collected using the self-report method with the help of a Patient Description Form, the Heart Surgery Symptom Inventory (HSSI) and the Newcastle Satisfaction with Nursing Care Scale (NSNS). The data were analysed on the SPSS version 22.0 software. The data were analysed using numbers, percentages, minimum and maximum values, means and standard deviations, t-test, variance analysis and Pearson correlation analysis.

Results: The patients were found after their CABG surgery to experience pain, shortness of breath, fatigue, lack of appetite, nausea and woundrelated symptoms. The most common complaint of the patients after the surgery was sleep problems and the least common wound-related symptoms. The mean HSSI score of the participating patients was $71.22 \pm 31.39$ and the mean NSNS score $52.87 \pm 22.54$, which meant that the severity of their post-surgery symptoms and their satisfaction with care were at a moderate level. Post-surgery pain, lack of appetite, nausea and wound-related symptoms were found to have a statistically significant moderate negative correlation with care satisfaction $(p<0.05)$ and shortness of breath, fatigue and insomnia to have a statistically significant strong negative correlation with care satisfaction $(p<0.05)$.

Conclusion: The results of this study revealed that patients who experienced less symptoms of pain, shortness of breath, fatigue, sleep disorders, lack of appetite, nausea, vomiting, and wound infection after a CABG surgery were more satisfied with the nursing care.
\end{abstract}

Keywords: Care Satisfaction, Nursing, Coronary Artery Bypass Graft, Symptoms

\section{INTRODUCTION}

According to the World Health Organization (WHO), noncommunicable diseases (NCDS) cause deaths at global, regional and national levels. The WHO 2017 data shows that 40 million people die every year due to NCDS, which constitute $70 \%$ of all deaths worldwide. In 2015, 37\% of NCDassociated deaths were caused by cardiovascular diseases (1). They accounted for 1.8 million deaths in European Union (EU) countries and 3.9 million deaths in whole Europe (2). Global deaths due to cardiovascular diseases are estimated to reach 22.2 million in 2030 (3).

The most widely used treatment method for CAD is the Coronary Artery Bypass Graft (CABG) surgery (4). The number of people who undergo a CABG operation annually is estimated to be 400,000 in the U.S. and 20,000 in Turkey $(5,6)$.

CABG is a major surgery and many symptoms can be seen in patients after the operation. These symptoms include respiratory, cardiovascular, neurological, renal, gastrointestinal and wound-related problems, fluid-electrolyte imbalance, pain, anxiety, insomnia, and fatigue (7-10).

Considering possible postoperative CABG symptoms, the nursing care to be provided in the process of recovery becomes extremely important $(11,13)$. The goal of nursing care after a CABG surgery is to prevent symptoms, to raise quality of life, and to establish patients' homeostatic equilibrium to ensure speedy recovery and discharge (14). The most fundamental indicator of quality nursing care is the satisfaction with care (15).

With the qualified nursing care provided in the early postoperative period, symptoms decrease and care satisfaction increases $(15,16,17)$. In a study made by Aydın (2014), patients who experienced less symptoms in the postoperative period have been reported to have better care satisfaction (18). Other studies have also reported that patients who experienced less pain in the postoperative 
period were satisfied with nursing care and had a faster recovery $(19,20)$. Another study has also found that patients who had good quality night sleep were more satisfied with nursing care (21). Good quality sleep also accelerates postoperative wound healing process (20). Yoon et al. (2015) have reported in their study dealing with wound care that patients who had more satisfaction with care had less symptoms developing in their wound site (22).

No study was found in the literature investigating the effect of symptoms seen in patients who had a CABG surgery on their care satisfaction. Therefore, by identifying the effect of the symptoms seen in patients who had a CABG operation on care satisfaction, this study is intended to provide guidance to nurses who will give care to this patient group and contribute to the literature.

\section{METHODS}

\subsection{Design}

This study is a descriptive research. The study was conducted in 2 hospitals, one state university hospital and one foundation university hospital in Istanbul between December 2018 and May 2019. According to 2017 data, 502 patients underwent a CABG operation in the state university hospital in a year and 61 patients in the foundation university hospital. The study population consisted of patients who had a CABG operation in these university hospitals in Istanbul. The power analysis performed suggested that at least 152 patients should be included in the study to achieve a significance level of 0.05 , a confidence interval of $95 \%$ and a power of $80 \%$ (23). Accordingly, no sampling was attempted and 176 patients were included in the sample from those who had a CABG operation for the first time, whose hospital stay did not exceed 10 days, who volunteered to take part in the study, and who was aged 18 years and over, conscious with no communication problems and agreed to take part in the study.

\subsection{Measures}

The study data were collected using the Patient Description Form, Heart Surgery Symptom Inventory, and Newcastle Satisfaction with Nursing Care Scale.

\section{Patient Description Form}

Prepared by the investigator, this form consisted of 20 questions in total, 9 questions about the demographic characteristics of the patients who had a CABG operation, such as age, gender, occupation, and education status and 11 questions about the disease and postoperative peculiarities.

\section{Heart Surgery Symptom Inventory (HSSI)}

HSSI was developed by LaPier and Jung (2002) to assess symptoms seen in patients after an open heart surgery (24). Its validity and reliability study in Turkish was performed by Altınok and Sağlam (2018) (25). The Turkish version of HSSI consists of a single scale with 35 items. The inventory is of a Likert-type and the symptoms are rated between 0 and 4 as "None", "Very Little", "Moderate", "Many", and "Quite Many".
The scores obtainable from the inventory range between 0 and 140 . With higher scores, the severity of symptoms increases. There are no reverse items in the inventory and its Cronbach alpha coefficient is 0.96.23 The Cronbach alpha coefficient of HSSI was found to be 0.98 in this study.

\section{Newcastle Satisfaction with Nursing Care Scale (NSNS)}

NSNS was developed by Thomas et al. (1996) (26). The validity and reliability study of the scale in Turkish was performed by Akın and Erdoğan (2006) (27). It is a 5-point Likert-type scale with a single scale and 19 items measuring nursing care. The scoring used to reveal satisfaction includes "1. Not at all satisfied, 2. Barely satisfied, 3. Quite satisfied, 4. Very satisfied, 5. Completely satisfied". The scoring involves summing the responses marked across the items and transforming them to 100 to obtain an overall score of $0-100$. An overall score of 100 shows that the patient is satisfied with all aspects of nursing care. The Cronbach alpha coefficient of the scale is 0.94.26 The Cronbach alpha coefficient of NSNS was found to be 0.98 in this study.

\subsection{Data Collection}

To collect data, patients who had a CABG operation and agreed to take part in the study were interviewed in their clinics before their discharge. The patients were informed about the study. The patients who agreed to take part in the study were asked to read and sign an Informed Consent Form. After reading and signing the informed consent form, the patients were administered the Patient Description Form, HSSI and NSNS on the basis of self-report.

\subsection{Analysis}

The data were analysed on the SPSS 22.0 package program. In data analysis, numbers, percentages, minimum and maximum values, means and standard deviations, t-test, variance analysis and Pearson correlation analysis were used.

\subsection{Ethical Considerations}

Before commencing the study, permission was obtained from the Ethics Committee of Maltepe University, Health Sciences Institute (Decision No: 2018/07-05) and from the Istanbul Provincial Health Directorate to be able to conduct the study in a state university hospital (Decision No: 16867222604.01.01). Permission was also obtained from the ethics committee of the foundation university hospital to be able to conduct the study (Decision No: 2019/10-2). Necessary permissions were obtained to use the Heart Surgery Symptom Inventory and the Newcastle Satisfaction with Nursing Care Scale. Written and verbal consents were obtained from the patients who agreed to participate in the study.

\section{RESULTS}

Of the patients, $59.1 \%$ were male, $84.1 \%$ married, $52.3 \%$ had income equal to expenses, and $28.4 \%$ were university graduates. Of the patients, $75 \%$ had health insurance 
and $57.4 \%$ lived in a nuclear family. The mean age of the participants was $62.09 \pm 9.28$ and $47.7 \%$ of them had undergone a prior operation once and $71 \%$ have not stayed in intensive care before. Of the patients, $59.1 \%$ had a comorbid chronic disease and $85.2 \%$ were smokers. Of the patients, $82.4 \%$ did not use alcohol, $73.9 \%$ did not exercise regularly, $42.6 \%$ had their 3 vessels replaced, and $84.1 \%$ stayed in intensive care for 24 hours (Table 1, 2). The patients' mean HSSI score was $71.22 \pm 31.39$ and mean NSNS score $52.87 \pm 22.54$ (Table 3 ). The most common symptom of the patients was insomnia $(2.4489 \pm 1.06)$ and the least common wound-related symptoms $(1.7614 \pm 1.09)$ (Table 4). The pain, lack of appetite-nausea and wound-related symptom scores were found to have a statistically significant moderate negative correlation with the NSNS score $(p<0.05)$ and the shortness of breath, fatigue and insomnia scores to have a statistically significant strong negative correlation with the NSNS score $(p<0.05)$. There was also a statistically significant, high level negative correlation between the HSSI total score and the NSNS total score $(p<0.05)$. As the HSSI total score decreased, the NSNS total score increased (Table 5).

Table 1. Distribution of descriptive characteristics of participants $(n=176)$

\begin{tabular}{|c|c|c|c|c|}
\hline \multicolumn{2}{|l|}{$\begin{array}{l}\text { Descriptive } \\
\text { Characteristics }\end{array}$} & n & \multicolumn{2}{|c|}{$\%$} \\
\hline \multirow[t]{2}{*}{ Gender } & Male & 104 & 59 & .1 \\
\hline & Female & 72 & 40 & .9 \\
\hline \multirow[t]{3}{*}{ Marital status } & Married & 148 & 84 & 1 \\
\hline & Single & 28 & 15 & .9 \\
\hline & Income less than expenses & 44 & 25 & 0 \\
\hline \multirow[t]{4}{*}{ Income Level } & Income equal to expenses & 92 & 52 & .3 \\
\hline & Income more than expenses & 40 & 22 & .7 \\
\hline & Able to read and write & 29 & 16 & .5 \\
\hline & Primary school & 41 & 23 & .3 \\
\hline \multirow[t]{3}{*}{ Education Status } & High school & 44 & 25 & 0 \\
\hline & University & 50 & 28 & 4 \\
\hline & Postgraduate & 12 & 6. & 8 \\
\hline \multirow{2}{*}{$\begin{array}{l}\text { Health } \\
\text { Insurance }\end{array}$} & Yes & 132 & 75 & .0 \\
\hline & No & 44 & 25 & .0 \\
\hline \multirow[t]{3}{*}{ Family Type } & $\begin{array}{l}\text { Nuclear } \\
\text { Broad }\end{array}$ & $\begin{array}{c}101 \\
52\end{array}$ & $\begin{array}{l}57 \\
29\end{array}$ & $\begin{array}{l}.4 \\
.5\end{array}$ \\
\hline & Fragmented & 23 & 13 & .1 \\
\hline & Spouse & 93 & 52 & .8 \\
\hline \multirow[t]{4}{*}{ Household } & Spouse and children & 55 & 31 & .3 \\
\hline & Alone & 15 & 8. & 5 \\
\hline & Children & 13 & 7. & 4 \\
\hline & Yes, I work & 13 & 7. & 4 \\
\hline \multirow{2}{*}{$\begin{array}{l}\text { Employment } \\
\text { Status }\end{array}$} & No, I don't work & 163 & 92 & .6 \\
\hline & Min. & Max. & Mean & SD \\
\hline Age & 45 & 83 & 62.09 & 9.28 \\
\hline $\begin{array}{l}\text { Duration of } \\
\text { Disease (Years) }\end{array}$ & 0 & 20 & 6.82 & 3.94 \\
\hline
\end{tabular}

Table 2. Distribution of disease-related and postoperative characteristics of patients ( $n=176$ )

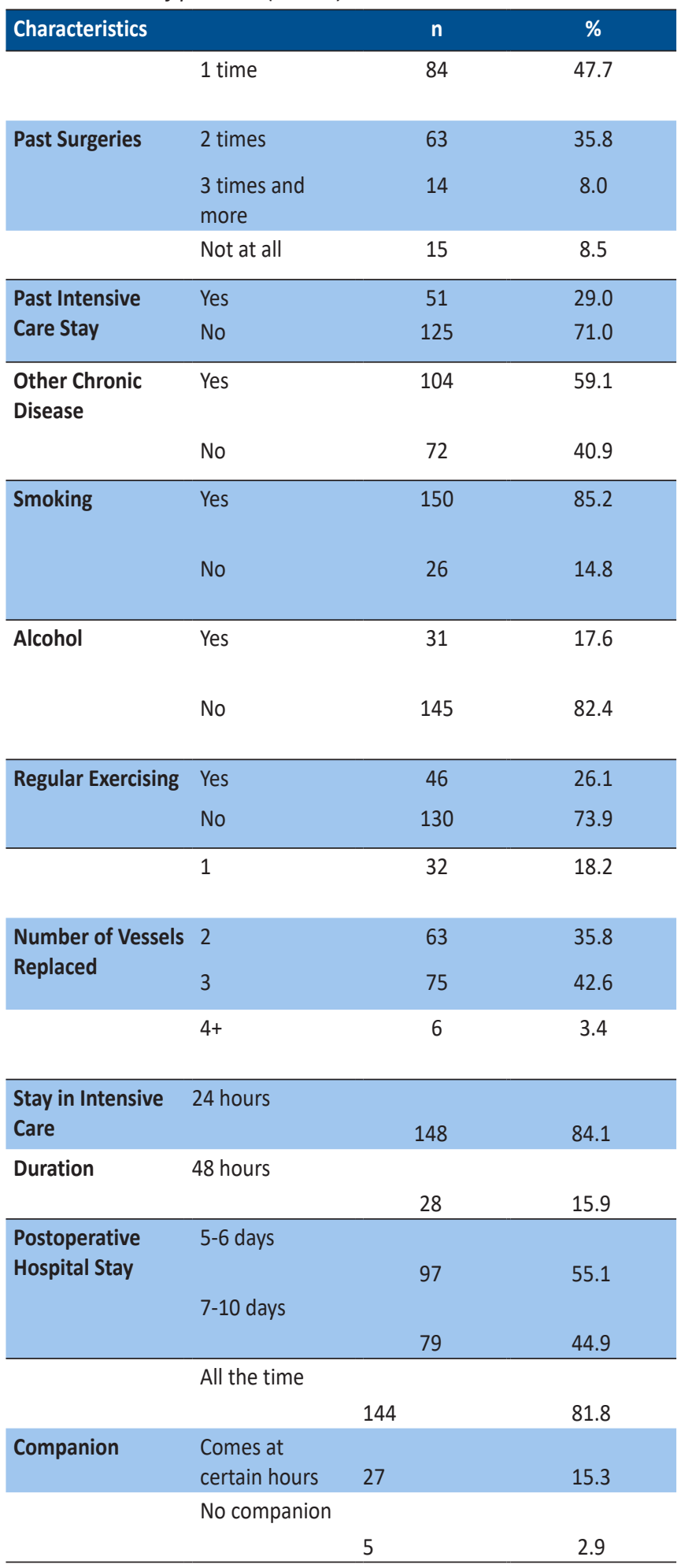

Table 3. Mean total scores obtained by patients from the heart surgery symptom inventory and the newcastle satisfaction with nursing care scale $(n=176)$

\begin{tabular}{lcccc} 
& Min. & Max. & Mean & SD \\
\hline Heart Surgery Symptom Inventory & 7 & 140 & 71.22 & 31.39 \\
\hline $\begin{array}{l}\text { Newcastle Satisfaction with } \\
\text { Nursing Care Scale }\end{array}$ & 20 & 100 & 52.87 & 22.54 \\
\hline
\end{tabular}


Table 4. Mean symptom scores obtained by patients from the heart surgery symptom inventory $(n=176)$

\begin{tabular}{lcccc}
\hline & Min. & Max. & Mean & SD \\
\hline Symptoms & & & & \\
\hline Pain & .00 & 4.00 & 1.9943 & 1.05558 \\
\hline Shortness of Breath & .00 & 4.00 & 2.1705 & 1.1724 \\
\hline Fatigue & .00 & 4.00 & 2.3352 & 1.09341 \\
\hline Insomnia & .00 & 4.00 & 2.4489 & 1.06781 \\
\hline Lack of appetite-Nausea & .00 & 4.00 & 2.1307 & 0.97978 \\
\hline $\begin{array}{l}\text { Wound-Related } \\
\text { Symptoms }\end{array}$ & .00 & 4.00 & 1.7614 & 1.09539 \\
\hline
\end{tabular}

Table 5. Correlation between patients' post-operative symptoms and care satisfaction $(n=176)$

\begin{tabular}{lcc} 
& Newcastle Satisfaction with Nursing Care \\
& \multicolumn{2}{c}{ Scale } \\
\hline Symptoms & $\mathrm{r}^{*}$ & $\mathrm{p}$ \\
\hline Pain & -0.729 & $\mathbf{0 . 0 0 0}$ \\
\hline Shortness of Breath & -0.823 & $\mathbf{0 . 0 0 0}$ \\
\hline Fatigue & -0.805 & $\mathbf{0 . 0 0 0}$ \\
\hline Insomnia & -0.782 & $\mathbf{0 , 0 0 0}$ \\
\hline Lack of appetite-Nausea & -0.682 & $\mathbf{0 . 0 0 0}$ \\
\hline Wound-Related Symptoms & -0.748 & $\mathbf{0 . 0 0 0}$ \\
\hline HSSI Total Score & -0.900 & $\mathbf{0 . 0 0 0}$ \\
\hline *Pearson correlation analysis & & $p<0.05$
\end{tabular}

\section{DISCUSSION}

CABG surgery is one of the most widely used surgeries across the world and is one of the most effective and reliable treatment options for CAD (28). CABG surgery is a major procedure and many symptoms can be seen in patients in the postoperative period. These symptoms include respiratory system symptoms, GIS symptoms, cardiovascular system symptoms, neurological symptoms, renal symptoms, woundrelated symptoms, fluid-electrolyte imbalance, pain, anxiety, insomnia, and fatigue (7-10). In this study, the patients were found to experience pain, shortness of breath, fatigue, insomnia, lack of appetite-nausea, and wound site-related symptoms in the postoperative period.

It has been reported in the literature that patients with high levels of pain had lower satisfaction with nursing care and the recovery process of pain slowed down $(17,18)$. It has also been reported that when pain cannot be controlled, the risk of developing other symptoms increased and the comfort of patients declined in the postoperative period (31). In this study, the patients who had more pain were found to have a lower level of care satisfaction. Lower care satisfaction in patients with severe pain may have arisen from the failure to exercise effective pain management in the early postoperative period.

Patients who experienced less shortness of breath were found to have better care satisfaction in this study. Shortness of breath is one of the common symptoms seen in patients in the postoperative period (32). In a study made by Treat and Lindquist (2007) on CABG patients, pulmonary symptoms were found to be associated with care satisfaction (33). Other studies have also confirmed that pulmonary symptoms restrict physical activity tolerance in patients resulting in decreased patient comfort and quality of life (34). It is stated in a study made by Yilmaz (2002) that when pulmonary symptoms are controlled, patients' care satisfaction improves (35). It can be said that the patients who did not experience shortness of breath or who experienced it less in this study had better care satisfaction as a result of effective nursing care.

Insomnia and fatigue are among the common symptoms seen after a CABG operation (36). Nursing care is reported to be extremely important in improving sleep quality of patients (37). Some studies have found that patients who have good quality sleep are satisfied with the nursing care provided at night $(19,38)$. In a study made with patients who underwent a CABG surgery, postoperative insomnia and fatigue symptoms were found to be associated with care satisfaction (32). It was also found in this study that patients who experienced less insomnia and fatigue had better nursing care satisfaction. This can be explained by the fact that patients who are made subject to symptom management and whose sleep is kept under control experience less fatigue and thus they report better care satisfaction.

Nausea-vomiting is one of the frequent symptoms experienced by patients in the postoperative period (39). Sung (2016) has reported in their study that nausea-vomiting symptom seen in the postoperative period was associated with care satisfaction (40). In another study made by Royse et al. (2013), GIS symptoms that cannot be controlled were found to reduce nursing care satisfaction (41). It was also found in this study that the patients who experienced less nausea-vomiting symptoms had better care satisfaction. It can be said that the quality of the nursing care provided is directly proportional to care satisfaction in patients who are closely monitored for nausea-vomiting and are given medical treatment and nursing care when necessary in the postoperative period.

It was found in this study that the patients who developed less wound-related symptoms were more satisfied with the care. Studies have reported that wound-related symptoms that may develop in patients in the postoperative period was associated with the quality of care and thus care satisfaction and patients who did not develop a symptom in their wound site were more satisfied with care $(22,42,43)$. Woundrelated symptoms prolong the recovery process of patients and therefore their time of hospitalization and prolonged hospital stay decrease patients' care satisfaction $(44,45)$. The reason for the patients who experienced less woundrelated symptoms in the present study to have better care satisfaction was that adequate and appropriate care was given to these patients, the wound care provided diminished their wound-related symptoms (infection, fever, discharge) and in this way, the patients who experienced less symptoms were more satisfied with the care. 
In a study carried out with patients who underwent an operation, the symptoms seen after the operation was reported to be associated with nursing care satisfaction (17). Another study also reported that patients who experienced less postoperative symptoms were more satisfied with nursing care (18). Another study made by Velanovich (2004) has reported that patients whose symptom severity was higher in the postoperative period had a slower recovery process and their care satisfaction was lower (46). Similarly, it was also found in this study that the patients experienced moderate symptoms in the postoperative period, they were satisfied with the nursing care at a moderate level and as the symptoms experienced by the patients decreased, their care satisfaction increased. The reason why the patients' care satisfaction improved as the symptoms seen in the postoperative period decreased in this study can be explained by the fact that the nursing care provided in the postoperative period reduced the symptoms seen in the patients, which affected care satisfaction positively.

The limitations of this study include that it was conducted only in the city of Istanbul and that there were only limited number of studies investigating the relationship between postoperative CABG symptoms and care satisfaction.

\section{CONCLUSION}

The results of this study revealed that patients who experienced less symptoms of pain, shortness of breath, fatigue, sleep disorders, lack of appetite, nausea, vomiting, and wound infection after a CABG surgery were more satisfied with the nursing care. Based on these results, our recommendations would be to raise awareness among nurses that symptoms seen in this patient group can affect care satisfaction and to motivate nurses to provide effective nursing care to patients considering that reduced symptoms lead to better care satisfaction and to employ effective symptom management to reduce symptoms. Conducting similar studies in multiple centres with larger samples is also recommended.

\section{Financial Disclosure}

This research did not receive any specific grant from funding agencies in the public, commercial, or not-for-profit sectors.

\section{Author contributions}

Bozkurt T and Sağlam R contributed to planning the research and writing the manuscript. Bozkurt $\mathrm{T}$ collected the data and Sağlam $R$ reviewed the manuscript with constructive criticisms.

\section{REFERENCES}

[1] World Health Organization (2017). On World Heart Day WHO calls for accelerated action to prevent the world's leading global killer. Available from https://www.who.int/news-room/ fact-sheets/detail/cardiovascular-diseases-(cvds).
[2] Wilkins E, Wilson L, Wickramasinghe K, Bhatnagar P, Leal J, Luengo-Fernandez R, Burns R, Rayner M, Townsend N. European Cardiovascular Disease Statistics 2017. European Heart Network, Brussels.

[3] Şencan I, Keskinkılıç B, Ekinci B, Öztemel A, Sarıoğlu G. Turkey Cardiovascular Diseases Prevention and Control Program Action Plan 2015-2020. Ankara: T.C. Ministry of Health (Turkish).

[4] Badır A, Demir Korkmaz F. Coronary Diseases Karadakovan A, Aslan Eti, F (Ed.). Care in Internal and Surgical Diseases. Academician Medical Bookstore, 431479; 2014 (Turkish).

[5] Alexander JH, Peter K, Smith, MD. Coronary artery bypass grafting. The New England. J Med 2016; 374 (20):1954-64.

[6] Demirkıran G, Uzun Ö. Post-discharge learning needs of patients who had undergone coronary artery bypass grafting surgery. Ege University Faculty of Nursing Journal 2012; 28 (1): 1-12 (Turkish).

[7] Konuralp C, İdiz M. Systematic approach on postoperative care of the cardiac surgical patients. Anatolia J Cardiol 2003; 3 (1): 156-161 (Turkish).

[8] Tromp F, Vandulmen S, Weert J. Inter disciplinary preoperative patient education in cardiac surgery. J Adv Nurs 2004; 47 (2): 212-222.

[9] Yorke J, Cardiothor GD, Wallis M, Cert C, Mclean B, Cert G. Patients' perceptions of pain management after cardiac surgery in, Australian critical care unit. Heart Lung 2004; 33(1):33-41.

[10] Barnason S, Zimmerman L, Anderson A, Mohr-Burt, S, Nieveen, $J$. Functional status outcomes of patients with a coronary artery bypass graft over time. Heart Lung 2000; 29 (1): 33-46.

[11] Yıldırım N, Atalay M. Evaluation of the quality of life of patients with coronary artery bypass surgery. J Res Dev Nurs 2002; 4 (1): 64-52 (Turkish).

[12] Avcı Işık S. Coronary artery diseases surgery and nursing care. Clin J Turkey, 2018; 4(1): 8-19 (Turkish).

[13] Ozcan H, Findik UY, Sut N. Information level of patients in discharge training given by nurses following open heart surgery. Int J Nurs Pract 2010 16: 289-294 (Turkish).

[14] Hillis LD, Smith PK, Anderson JL, Bittl JA. Guideline for coronary artery bypass graft surgery: executive summary a report of the american college of cardiology foundation/american heart association task force on practice guidelines developed. Circulation 2011; (124):2610-2642

[15] Şendir M, Büyükyılmaz F, Yazgan G, Bakan N, Mutlu A, Tekin F. Evaluation of experience and satisfaction with nursing care in orthopedic and traumatology patients. Florence Nightingale Journal Nursing 2012; 20(1): 35-42 (Turkish).

[16] Workman ML, Ignatavicius DD. Medical surgical nursing critical thinking for collaborative care, 4 th ed. 38 . Philadelphia: W B Saunders Co; 2001.

[17] Sillero A, Zabalegui A. Satisfaction of surgical patients with perioperative nursing care in a Spanish tertiary care hospital. SAGE Open Med 2018; 6:1-9.

[18] Aydın Z, Özer N. Evaluations of nursing care of patients hospitalized during the postoperative period. The Macro Journals Conference on Health and Medicine-Monte Carlo, 2015 May 26-27 th; Monaco; 2015. p.21-22.

[19] Woldehaimanot TE, Eshetie TC, Kerie MW. Postoperative pain management among surgically treated patients in an ethiopian hospital. Plos One 2014; 9 (7): E102835. 
[20] Acar K, Acar H, Demir F, Eti Aslan, F. Determining the satisfaction level of patients after postsurgical pain treatment. Anatolia J Nurs Health Sci 2016; 19: 2 (Turkish).

[21] Acaroğlu R., Savcı C, Bilir A, Kaya H, Şendir M, Örenli M, Temel Z. Evaluation of nursing care provided at night in the neurosurgery clinic. Maltepe University J Nurs Sci and Art 2007; 2(1): 2-7 (Turkish).

[22] Yoon S, Bae S, Namgung H, Park D. Clinical Trial on the incidence of wound infection and patient satisfaction after stoma closure: Comparison of Two Skin Closure Techniques. Ann Coloproctol 2015; 31(1): 29-33.

[23] Munro BH. Statistical methods for health care research. Philadelphia: Lippincott Williams \&Wilkins; 2005. p.351-76.

[24] LaPier TK, Jung C. Development and content validity of the Heart Surgery Symptom Inventory. Acute Care Perspectives 2002; 11(2):5-12.

[25] Altınok D, Sağlam R, Valıdıty and reliability of the heart surgery symptom inventory in Turkısh language. Maltepe University, Health Sciences Institute, Master Thesis. 2018 (Turkish).

[26] Thomas LH, McColl E, Priest J, Bond S, Boys J. Newcastle Satisfaction with Nursing Scales: and Instrument for Quality Assessments of Nursing Care. J Qual Health Care 1996; 5: 6772.

[27] Akın S, Erdoğan S. The Turkish version of the newcastle satisfaction with nursing care used on medical and surgical patients. J Clin Nurs 2007; 16: 646-653 (Turkish).

[28] Melly L, Torregrossa G, Lee T, Jansens JL, Puskas JD. Fifty years of coronary artery bypass grafting. J Thorac Dis 2018; 10(3): 1960-1967.

[29] Eti Aslan F, Demir Korkmaz F, Karabacak Ü. Pain in cardiac surgery and the nursing approach. J Thorac Cardiovas Sur 2012; 20(1): 172-176 (Turkish).

[30] Cogan, J, Ouimette MF , Vargas Schaffer G, Yegin Z. Deschamps A, Denault A. Patient attitudes and beliefs regarding pain medication after cardiac surgery: barriers to adequate pain management. Pain Manag Nurs 2014; 15(3):574-579.

[31] Gürler H, Yılmaz M. Nursing approaches toward postoperative pain of patients: Patients' options. J Pain 2011; 23(2): 71-79 (Turkish).

[32] Devecel Akkuş G, Şenturan L. Examining the relationship between atelectasis may develop in the postoperative period of open heart surgery before the breathing exercises. Halic University. Health Sciences Institute, Master Thesis. 2015 (Turkish).
[33] Treat DJ, Lindquist, R. Exercise, quality of life, and symptoms in men and women five to six years after coronary artery bypass graft surgery. Heart Lung 2007; 36(6):387-97.

[34] Bakalım T. Common complications after open heart surgery. Keçeligil, HT. (Ed.), 1st Edition. Istanbul, Capa Medical Bookstore, 1162 - 1151; 2004 (Turkish).

[35] Yılmaz M. Effect of the planned pre-operative teaching on the occurence of postoperative complications and patient satisfaction. J Nurs Res 2002;4 (1): 40-51 (Turkish).

[36] Roy SC. Roy Adaptation Model. Third Edition, Upper Saddle River, NJ: Prentice hall health. Nurs Sci Q 2009; 22 (3): 209211.

[37] Greve, H., Pedersen, P. (2016). Improving sleep after open heart surgery: effectiveness of nursing interventions. J Nurs Educ Pract 6 (3): 15-25.

[38] An H, Bronson R, Richard W, Valentina B, Idiris M. New onset of insomnia in hospitalized patients in general medical wards: incidence, causes, and resolution rate. J Community Hosp Intern Med Perspect 2017; 7 (5):309-313.

[39] Aktaş $Y$, Gürçayır D, Atalay C. Evidence based practices in postoperative nausea vomiting management. Dicle Med J 2018; 45 (3): 341-351 (Turkish).

[40] Sung Uk C. Is postoperative nausea and vomiting still a big "minor" problem? Korean J Anesthesiol 2016; 69(1):1-2.

[41] Royse CF, Chung F, Newman S, Stygall J, Wilkinson DJ. Predictors of patient satisfaction with anaesthesia and surgery care: a cohort study using the postoperative quality of recovery scale. Eur J Anaesthesiol 2013; 30 (3): 106-110.

[42] Kos M, Dziewa A, Ksykiewicz A, Drop B. Nursing care quality and postoperative wound infections. Pol J Public Health 2016; 126(1): 13-18.

[43] Qahtani SA, Critchley KA, Ngwakongnwi E. Patient satisfaction with aninterprofessional approach to wound care in Qatar. Public Health Open J 2017; 2 (2): 46-52.

[44] Xin Y, Heng Z, Zhe Z, Chenfei R, Yan Z, Yun W, Harlan M, Shengshou $\mathrm{H}$. Trends in mortality and major complications for patients undergoing coronary artery bypass grafting among Urban Teaching Hospitals in China: 2004 to 2013. Eur Heart J Qual Care Clin Outcomes 2017; 3 (4): 312-318.

[45] Aldemir K, Gürkan A, Yılmaz F, Karabey G. Examination of satisfaction from nursing care of inpatients in the surgical clinics. J Health Nurs Manag 2018; 5(3): 155-163 (Turkish).

[46] Velanovich, V. Using quality-of-life measurements to predict patient satisfaction outcomes for antireflux surgery. J Arch Surg 2004; 139(6): 621-62. 